\title{
A ROADMAP FOR INTEGRATION OF DESIGN-CONSTRUCTION DECISION MAKING
}

\author{
S.P. Sreenivas. Padala ${ }^{1}$, J. Uma Maheswari ${ }^{2}$ \\ 1Research Scholar, Civil Engineering Department, Indian Institute of Technology Delhi, New Delhi, India \\ 1Assistant Professor, Civil Engineering Department, Indian Institute of Technology Delhi, New Delhi, India
}

\begin{abstract}
It is a well-known fact that the design phase is fragmented from the construction phase primarily due to the differing insights of the two phases. In any construction project, the decisions in design take place without anticipating the constructability issues thereby resulting in changes, redesign, rework, errors, omissions, repetition or iteration. The ideal solution to overcome this issue is to integrate these two phases which are expected to be NP-Hard. Thus, the objective of the present study is to investigate an integration mechanism for construction projects. Integrated Project Delivery (IPD) is the recent buzz word in construction firms that has the potential features to integrate teams, processes and information. Although researchers had identified BIM (Building Information Modeling) as one of the potential IPD tools for addressing the design integration issues, still it is inadequate. Hence, in this study, two methods: point-based and set-based design are evaluated with the help of a hypothetical tall building design and construction case example. The pros and cons of these two approaches were also elaborated in this paper. A conceptual framework for integrating design and construction is proposed and challenges to implement Set-based design principles are discussed.
\end{abstract}

KeyWords: Fragmentation,Integration, Point-based design, Set-based design.

\section{INTRODUCTION}

Globally, design phase of AEC (Architecture, Engineering and Construction) projects are depicted as evolving, iterative, information-rich, etc. [1] while the construction phase is portrayed as labor-oriented, hazardous, risky, etc. Thus, the perceptions of design and construction phases of any AEC project vary tremendously and thus the two phases are highly fragmented. The reason behind this can be attributed to several reasons such as but not limited to a) functional design dependencies vs. physical construction dependencies, b) top-down design process vs. bottom-up construction process, c) information-rich design process flow vs. stringent/inflexible construction workflow process. In any construction project, life cycle starts typically from client requirements, design brief, until commissioning, handover, operation, and maintenance. Several stakeholders play a leading role in various phases of the project. These stakeholders within a subgroup have differing views on the entire project. Fig. 1 shows different views of stakeholders for tall building design and construction. With the fragmented nature of executing the AEC projects, decisions are made at each phase of the project without anticipating the impact on subsequent project phases (construction) [2]. Apparently, several rework, repair and redesign occur during theconstruction stage. Decision making incorporating construction knowledge in the design phase isa challenging problem. Thus, the objective of this paper is to explore an integration mechanism for design construction of AEC projectsthat can overcome the fragmented nature of construction project execution. The present study is limited to design-construction phase of the AEC project life cycle. Two methods - point based and set based design are elaboratedfor demonstrating the design-construction integration. A hypothetical case example on tallbuilding design and constructionis consideredforelucidating the integration concept.

\section{BACKGROUND}

This section elaborates the three existing approaches for integrating design and construction processes. It is divided into three sections - 2.1 Integration Management, 2.2 Pointbased design process, 2.3 Set-based design process.

\subsection{Integration Management}

Integration management is responsible for necessary coordination among all the project stakeholders. The primary function is to facilitate coordination between various disciplines such as architecture, civil, mechanical, fire and so on [3]. This function further facilitates for different sub-functions of the project such as scope management, time management, cost management, procurement management, etc. Integrated Project Delivery (IPD) is the recent strategy adopted by stakeholders in construction companies that have the potential features to integrate teams, processes, informationthroughout all the stages of the project execution $[4,5]$. As shown in figure 1, fragmentation problem can be solved when all phases are integrated and work for a common objective of a construction project. Although researchers had developed and recognized BIM (Building Information Modeling) as one of the potential tools for addressing the design integration issues [6], still it is inadequate. BIM should be 
viewed as a project delivery method, can enhance by integrating constructability concept in a design phase [7].

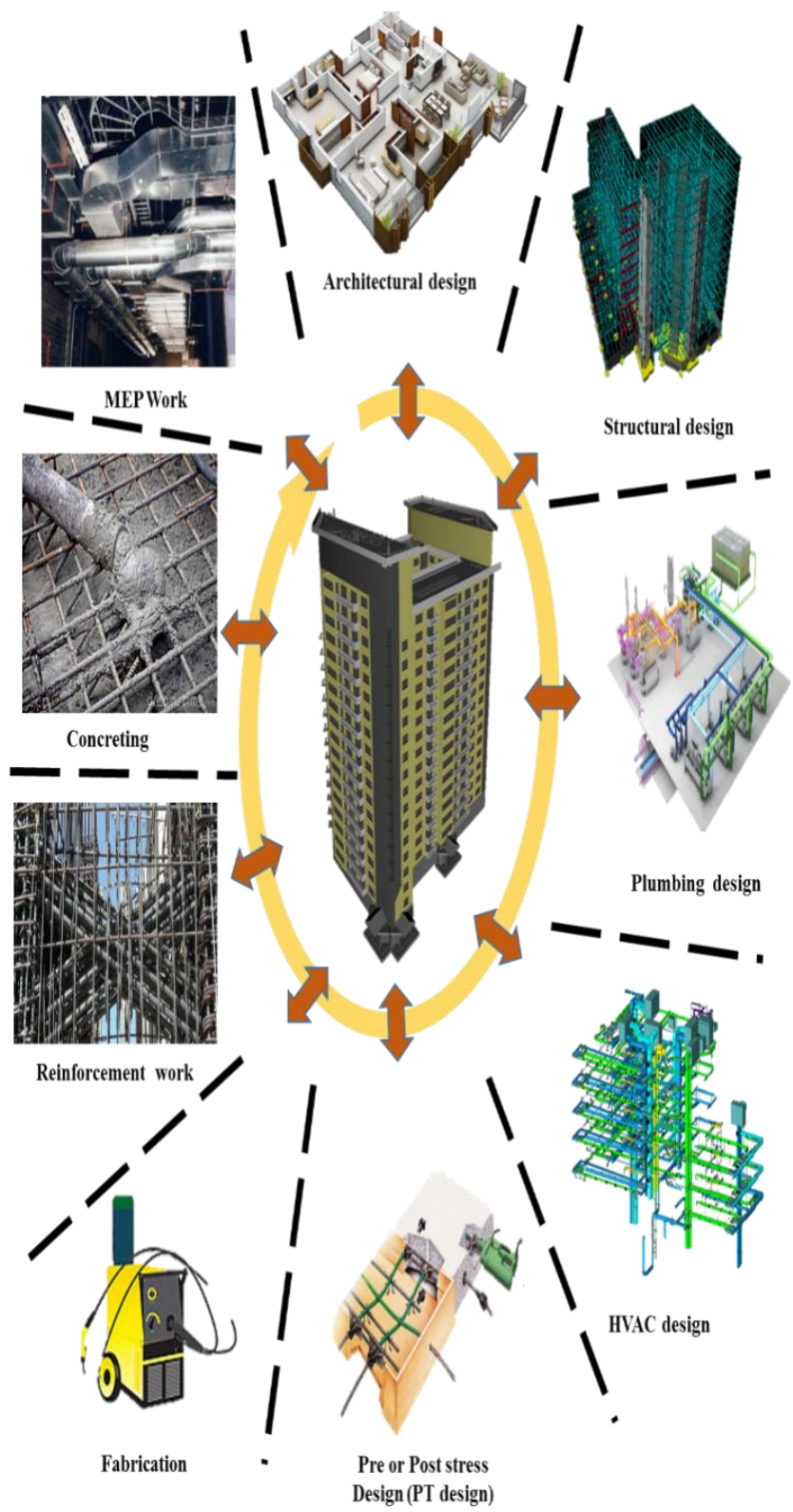

Fig-1: Fragmentation in the Tall Building Construction Projects

With the help of IPD strategy, BIM can be even more efficient when key stakeholders such as architects, designers, and construction professionals are jointly involved in a design phase

\subsection{Point-based design process}

The point-based design is a sequential decision-making process [6] as shown in Fig. 2. It includes selecting a one feasible or best design solution at each level in the design process and then refining that design solution while developing more details (construction, operation, and maintenance) in an iterative manner [2]. If the chosen design solution is not constructible, then redesign occurs. Since iterative process usually takes more time and increases the cost of a design process, there is an inclination to declare that design is complete at the end of the stipulated duration, whether or not the design has converged to a constructible design solution [8]. Iterative based design process increases the design development time and cost [9]. This sequential process also enforces constraints to determine the best construction methods in successor steps due to finalization of the design solution in predecessor step. Therefore, the point-based design has aninclination to increase the uncertainty in the decision making and increase the design cost through many iterations.

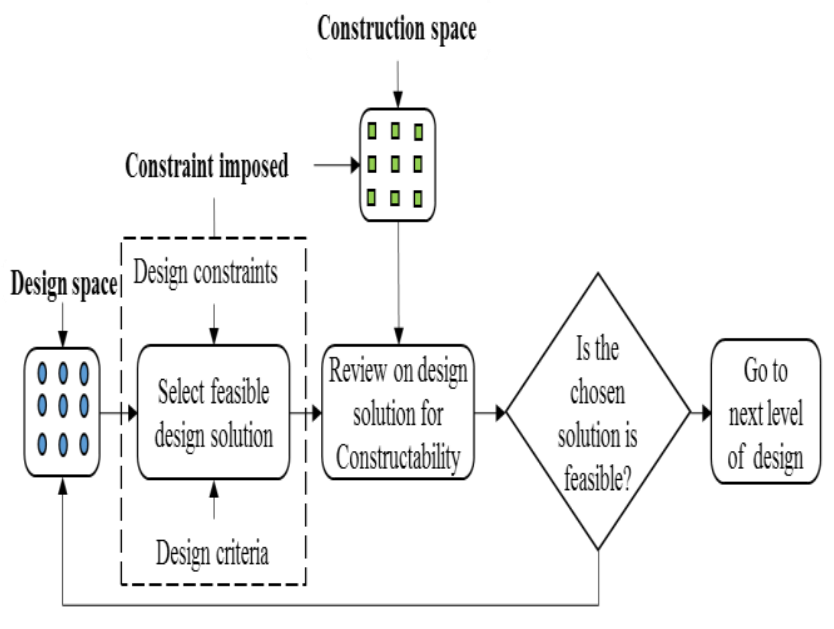

Selection of another solution

Fig-2: Point-based design of Tall building construction projects

If the chosen design solution satisfies construction requirements in the first iteration, then point based design is an economic decision-making process due to a limited period of involvement of several stakeholders. However, even it is economical and costs less for a design team, any redesign error occurrence in a construction phase will resultin overall project schedule and cost overrun.

\subsection{Set-Based Design Process}

Ward et al. [10] introduced a Set-Based Design (SBD), which was originally developed by Toyota production system. The set-based design works on principles of concurrent engineering principles which assesses design and construction processes simultaneously or in a parallel manner $[10,11]$ as shown in Fig.3. CE is a mechanism which reduces the uncertainty by performing simultaneous product and process development operations [12].The major difference between point-based design and SBD is working on a set of options (alternatives), rather than working on a single design solution then perform rework if it does not meet stated goals. SBD delays the convergence of final design solution by working on a set of all possible options (construction methods) and eliminates each solution which is infeasible [11]. Feasibility of construction can be analyzed concurrently from the beginning of design phase to generate constructible design solutions. Hence, SBD process decreases the uncertainty by delaying decisions till the last 
responsible moment [13]. It also eliminates the iterative way of the decision-making process. In tall buildings, SBD plays major role due to several alternatives are required to evaluate in design and construction. Parallel decision making is superior to point-based design regarding reducing redesigns or rework but inferior concerning the cost of implementing in the design phase since various stakeholders are required to participate from the inception. Although performing SBD process increases design duration and cost, it has potential to eliminate redesigns or rework in a construction stage which ultimately decreases the overall project schedule and cost overruns. Hence, SBD process evaluates design and construction processes concurrently for integration of design and construction and reduce uncertainty in a decision making.

\section{PROPOSED INTEGRATION FRAMEWORK FOR DESIGN AND CONSTRUCTION}

Point based and Set-based design approaches originated from manufacturing industry where product design and process design are directly linked. However, in construction projects, the relationships design and construction is not directly related, and there exists an indirect relationship. Construction projects (particularly tall buildings) classified into two stages of design and construction: 1. Permanent structure design and construction 2. Temporary structure design and construction. For example, in a tall building design and construction, permanent structure broadly consists of sub-structure: foundation, pedestal, columns, basement slab and in superstructure -columns, shear walls, non-loading masonry walls, slabs, staircases. These components serve a final function (for end users) of a building. Temporary structure in a building supports permanent structure construction of substructure and superstructure components. This temporary structure again classified into formwork (to support columns, walls, slabs construction), false work (to support working platform, workers load) and erection of equipment (for movement of materials). It supports permanent structure for a particular duration (unlike permanent structure functions for entire design life period). It provides intermediate functionality (for contractors) rather than final function to end users [14]. Therefore, intermediate functional requirements are also equally important to examine in the design phase along with final function requirements.

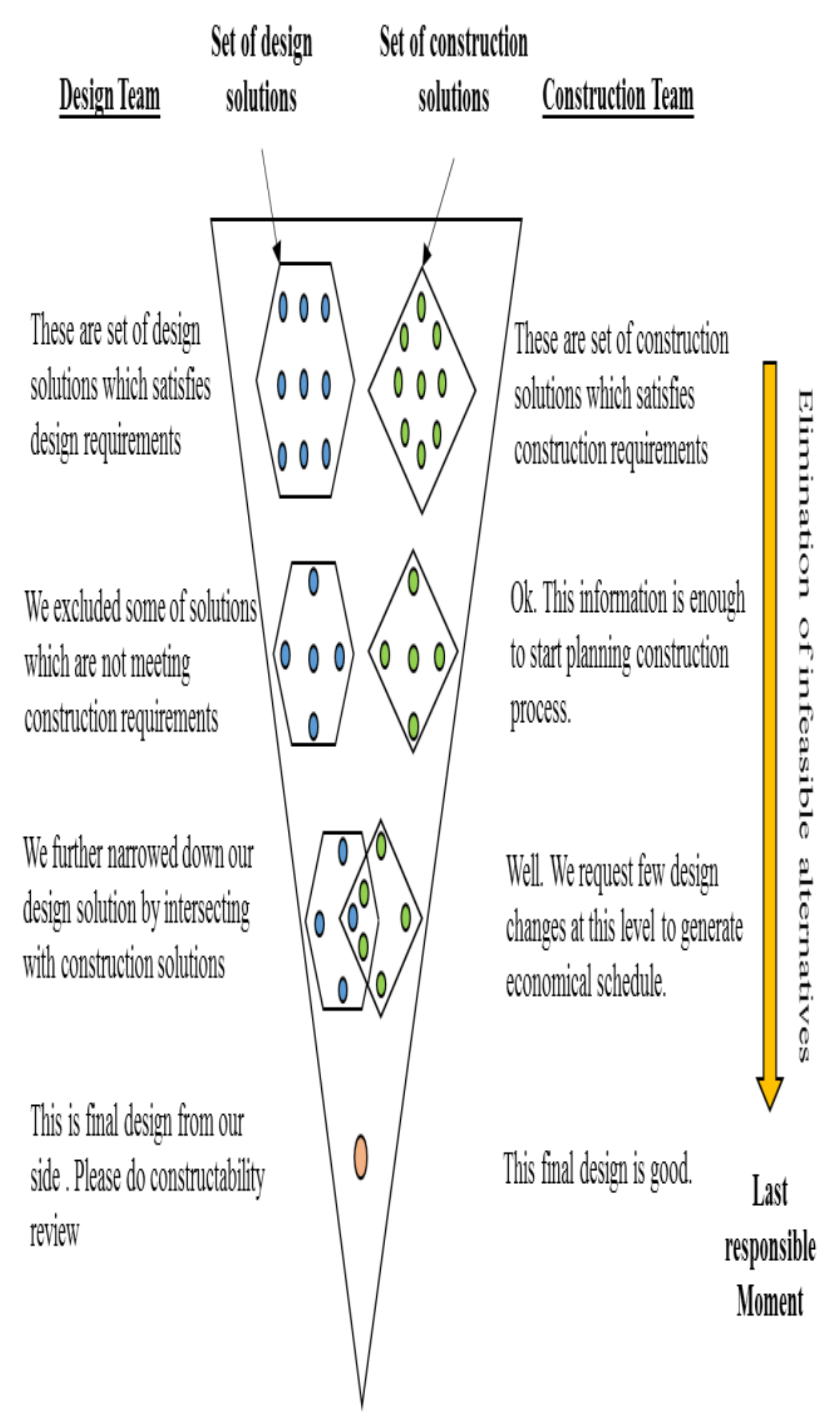

Fig-3: Set-Based Design of Tall Building Construction Projects

As shown in Fig.4, for illustration purpose in a tall building construction projects, permanent design and construction are indirectly related to each other. Permanent design requirements satisfy final functional requirements which can be achieved by proper selection of construction methods in permanent construction. However, to achieve final function, temporary structure design and construction requirements (intermediate functionality) are equally important to analyze in the design phase as they are directly linked to permanent structure design and construction as shown in Fig.4. Therefore, this proposed conceptual integration framework for tall buildings can enable better project planning.This proposed integration framework can be implemented by using SBD principles as it eliminates decision-makingin isolation and reduces redesign or rework. An SBD framework for integrating tallbuilding design and construction process is portrayed in Fig.5. It clearly shows, to evaluate alternatives for design and construction (permanent and temporary) using SBD approach, several teams are required to be involved, and the decisions made on design has an effect on construction and vice versa. 


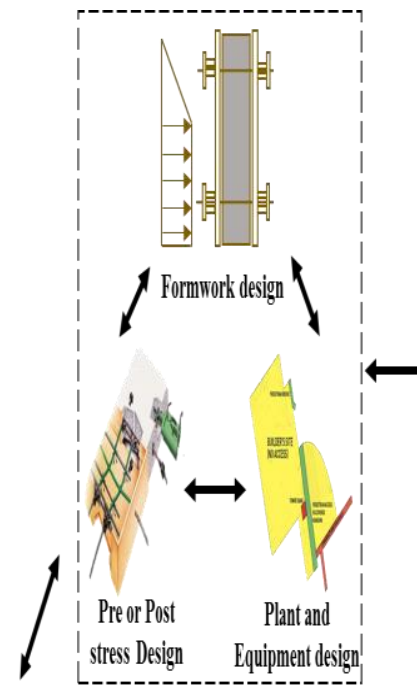

4b). Temporary Structure Design

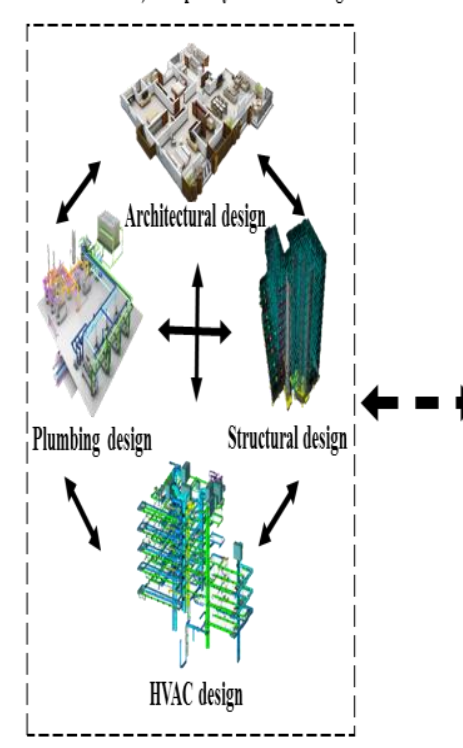

4a).Permanent Structure Design

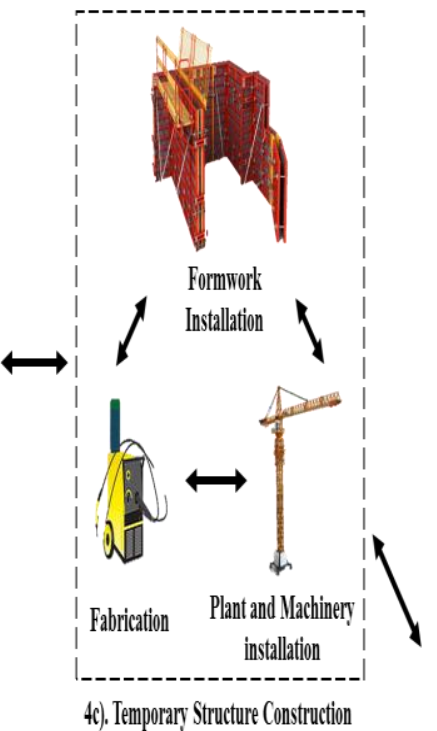

Temporary Structure Construction

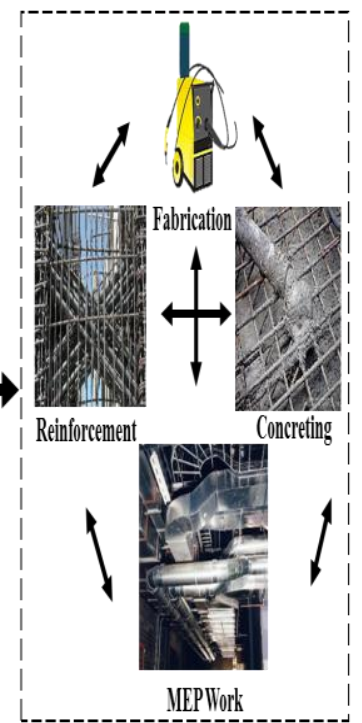

4d). Permanent Structure Construction

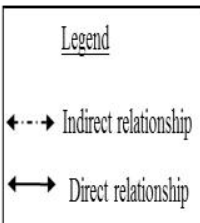

Fig-4: Proposed Conceptual Integration Framework for Tall Building Design and Construction

For example, as shown in Fig. 5, if designer selects the type of building (shear wall + flat slab system) based on the behavior of a structure, it will affect the choice of construction method selection (superstructure: Modular formwork or Table formwork). In some situations, there is a chance that no construction methods available to suit design requirements or costly to implement for chosen design solution. Hence, type of building has to be altered without compromising the purpose of it to suit construction requirements in addition to design requirements. In one particular case it was observed that the architect recommended planter in a balcony in every flat of theresidential project which forced thecontractor to change modular formwork (4-7 days floor cycle) to conventional formwork (10-15 days). Therefore, to implement SBD principles for integrating design and construction, it is first essential to understand dependencies/relationships between each decision (through the collaboration of designer, contractor, formwork designer, fabricator, and suppliers) while concurrently evaluating design and construction solutions.

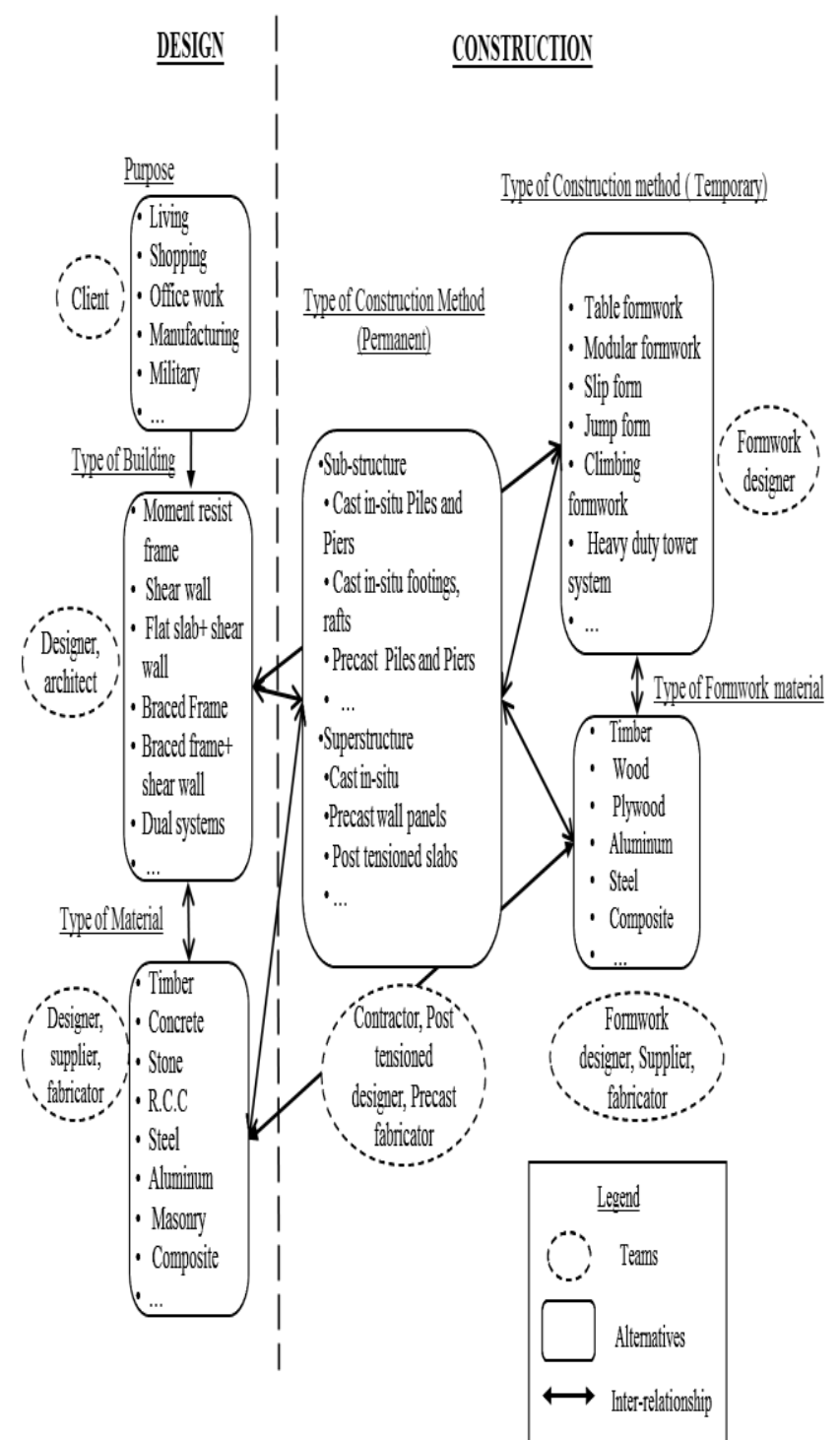

Fig-5: Set-Based Design Approach for Tall Building Design -Construction Integration.

\section{DISCUSSIONS AND SUMMARY}

Implementation of SBD process in thetall buildingprojects is challenging process since it has no detailed methodology to follow yet. Two essential steps are required to understand to implement SBD framework as shown in Fig.6. Initially, selection of best alternative which satisfies both design and construction requirements is a Multi-Criteria Decision Making (MCDM) problem. Several criteria in design and in construction are require to assess for deriving construction design solution. Further, to solve MCDM problem, several stakeholders as mentioned earlier in Fig 5, are required to 
involve for decision making.Therefore, aggregation of all stakeholders' preferences to one preference to choose the best design solution becomes a challenging problem which is called Group Decision Making (GDM).

This research study is aninitially effort to understand integration mechanism in AEC projects especially tall buildings. Two design decision-making process, the pointbased and SBD were reviewed which aids in generating constructible design solutions. SBD process has a potential to reduce uncertainty in decision making. There exist direct and indirect dependencies between design and construction decisions which have to analyze accurately while evaluating design and construction processes using SBD approach. A conceptual integration framework was proposed to address challenges in implementing SBD principles where further detailed methodology will be developed in future which can aid in solving MCDM and GDM problem for generating constructible design solutions.

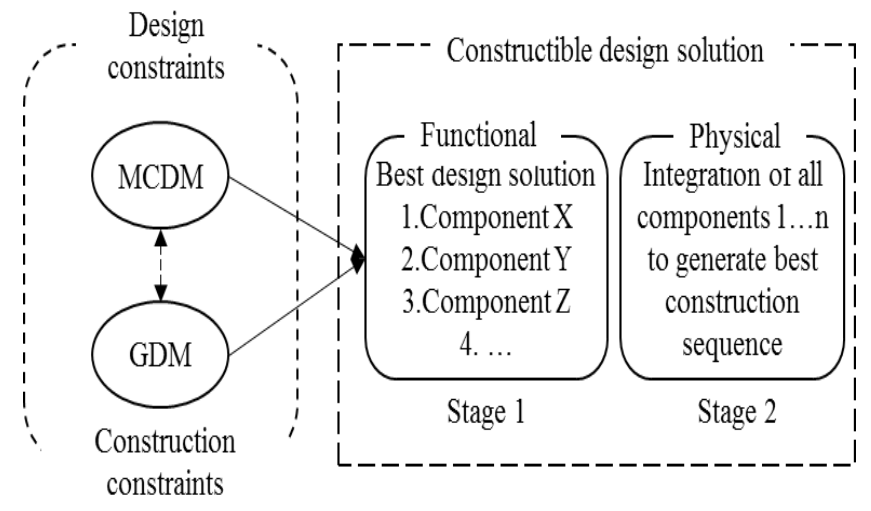

$\mathrm{MCDM}=$ Strength, stability, duration, cost, etc.

GDM = Architect, structural designer, formwork designer, fabricator, supplier, so on.

Fig-6:ConceptualFramework to Implement SBD Process.

\section{REFERENCES}

[1]. E. Zaneldin, E., Hegazy, T., Grierson, D, "Improving design coordination for building projects, II: A collaborative system.” J. Constr. Eng. Manage. 127 (4), pp. 330-336, 2001.

[2]. Parrish, K., Wong, J.-M., Tommelein, I. D., Stojadinovic, B, "Exploration of set-based design for reinforced concrete structures." In. Proceedings of 15th Conference of the International Group for Lean Construction, Pasquire, C. and Tzortzopoulous, P. (eds.), pp. 213-222. Michigan State University, East Lansing, MI, 2007.

[3]. Bureau of Indian Standards, "Construction Project Management - Guidelines Part 12 Integration Management-IS 15883 (Part 12).” BIS, New Delhi, India, 2015. Manuscript submitted for publication.

[4]. Gokhale, S, "Integrated project delivery method for trenchless projects." In. ICPTT 2011, Ma, B, Najafi, M, Jiang, G, Slavin, L. (eds.), pp. 604-614. ASCE, Beijing, China, 2011.
[5]. Garcia-Saenz, M, "From Fragmented to Integrated Project Design \& Delivery: Student's New abilities and Future Direction in Curriculum." In. Proceeding of 11th Latin American and Caribbean Conference for Engineering and Technology, pp.1-8. Cancun, Mexico, 2013.

[6]. Kent, D., Becerik-Gerber, B, "Understanding Construction Industry Experience and Attitudes toward Integrated Project Delivery." J. Constr. Eng. Manage. 136(8), pp.815-825, 2010.

[7]. Ruby, D, "Design Guide 23: Constructability of Structural Steel Buildings.”AISC, USA, 2005.

[8]. Singer, D. J., Doerry, N., Buckley, M. E, "What is setbased design?" NAV ENG J. 121(4), pp.31-43, 2009.

[9]. Terwiesch, C. Loch, C.H. De Meyer, A, "Exchanging Preliminary Information in Concurrent Engineering: Alternative Coordination Strategies." Organ. Sci. 13(4), pp.402-419, 2002.

[10]. Ward, A., Liker, J.K., Cristiano, J.J., Sobek II, D.K, "The Second Toyota Paradox: How Delaying Decisions Can Make Better Cars Faster." Sloan Management Review, pp. 43-61, Spring, 1995.

[11]. Lee, S.-I., Bae, J.-S., Cho, Y.S, "Efficiency analysis of Set-based Design with structural building information modelling (S-BIM) on high-rise building structures" Automat. Construc.23, pp.20-32, 2012.

[12]. Cleetus, K. J, "Definition of concurrent engineering. CERC Technical Report Series. Research Note, CERC-TR-RN-92- 003" Concurrent Engineering Research Centre, pp. 1-5. West Virginia University, Morgantown, 1992.

[13]. Ballard, G, "Positive vs negative iteration in design. In. Proceedings of 8th Annual Conference of the International. Group for Lean Construction" IGLC-6, International Group for Lean Construction, pp. 1-12. Brighton, U.K, 2000.

[14]. Song, Y., Chua, D, "Modeling of Functional Construction Requirements for Constructability Analysis" J. Constr. Eng. Manage.132 (12),pp.13141326, 2006.

\section{BIOGRAPHIES}
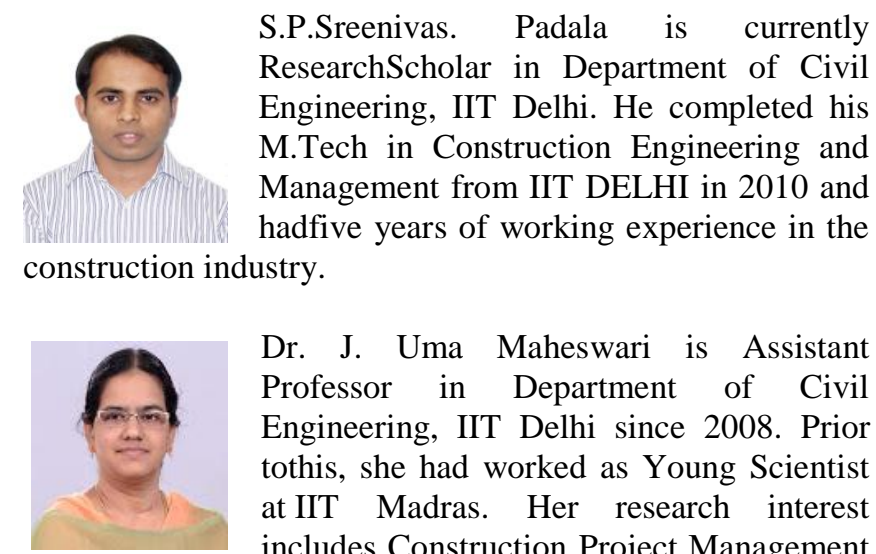

Dr. J. Uma Maheswari is Assistant Professor in Department of Civil Engineering, IIT Delhi since 2008. Prior tothis, she had worked as Young Scientist at IIT Madras. Her research interest includes Construction Project Management with aspecial focus on Design Management. She also received a Young Researcher Award fromPMI (Project Management Institute) India and the Best NICMAR Journal Paper Award for the year 2015. 